\title{
Large Cervico-facial Lipomas Revealing Launois Disease BENSAUDE
}

\author{
N.Belhaj ${ }^{1 *}$, I.Boumendil ${ }^{1}$, H.Rahim ${ }^{1}$, I. Allouch ${ }^{1}$, S.Nitassi ${ }^{2}$, A.Oujillal ${ }^{2}$, R.Bencheikh ${ }^{2}$, M.A.Benbouzid ${ }^{2}$, L.Essakalli ${ }^{2}$
}

\author{
${ }^{1}$ Resident physician in otorhinolaryngology, Department of Otorhinolaryngology, Head and Neck Surgery, Ibn Sina University Hospital, Rabat, \\ Morocco \\ ${ }^{2}$ Professor of otorhinolaryngology, Department of Otorhinolaryngology, Head and Neck Surgery, Ibn Sina University Hospital, Rabat, Morocco \\ ${ }^{3}$ Faculty of Medicine and Pharmacy of Rabat, Mohammed V University, Rabat, Morocco
}

DOI: $10.36347 /$ sjmcr.2020.v09i01.003

| Received: 29.11.2020 | Accepted: 12.12.2020 | Published: 08.01.2021

*Corresponding author: Belhaj Najoua

Abstract

Case Report

This is the case report of trans oral trans pharyngeal removal of air gun pellet which was accidentally fired into the mouth of a young gentleman while attempting to clean the gun. The gun pellet pierced the soft palate and dodged into the Cranio Vertebral Junction (CVJ) in the anterior aspect. Removing a foreign body dodged close to such a deep and vital area of the brain and spinal cord was a very challenging task from the part of Surgeons. The most difficult part of the whole scenario was the dilemma of whether to operate upon a patient who was totally preserved and remove a foreign body or to just observe the patient. We proceeded with the first option of surgical removal. The patient survived the surgery and was discharged without any focal neurological deficit.

Keywords: Trans pharyngeal exploration, Cranio Vertebral Junction, fire arm injury.

Copyright $\odot 2021$ The Author(s): This is an open-access article distributed under the terms of the Creative Commons Attribution 4.0 International License (CC BY-NC 4.0) which permits unrestricted use, distribution, and reproduction in any medium for non-commercial use provided the original author and source are credited.

\section{INTRODUCTION}

Launois-Bensaude disease is a rare pathology characterized by the presence of multiple nonencapsulated symmetrically arranged lipomas predominantly cervico-facial. It occurs mainly in men between 35 and 50 years old and is frequently associated with alcoholism, liver disease, glucose intolerance, hyper uricemia and cancer of the upper aero-digestive tract $[1,2]$.

\section{Case Report}

This is a 45-year-old HIV positive patient who has a history of chronic alcoholism with active smoking. the patient presented with masses in the back of the neck that spread to the para cervical region. which gradually increased in volume the biological assessment confirmed chronic alcoholism on the results of hepatic markers. In etiological assessment, MRI showed extensive cervico-facial lipomatosis involving the subcutaneous tissue, with many more individualizable lipomas and with vascular invasion, but without pathological contrast enhancement. From a pathological point of view, the patient underwent surgical excision of the lipomas, the evolution marked by the reappearance of lipomas, which is why liposuction was carried out twice (figure1) [3, 4].
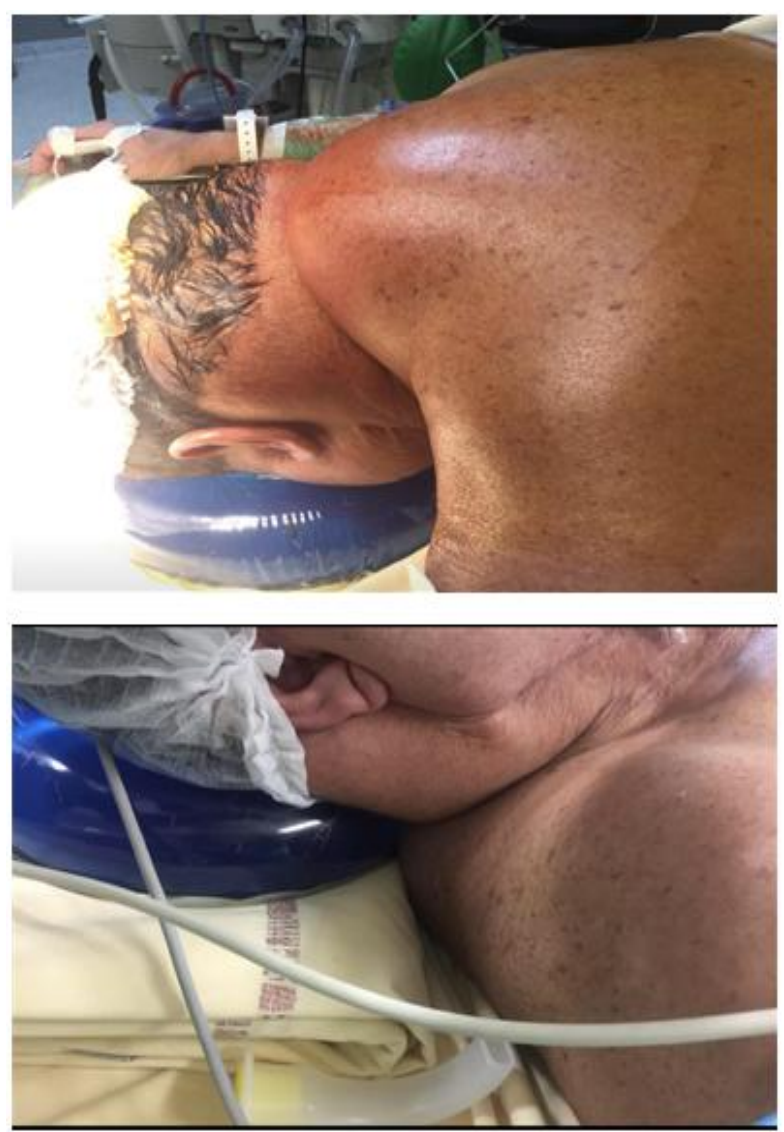

Fig-1.2: pictures of cervical and neck lipomas 


\section{DISCUSSION}

Launois-Bensaude disease is a benign, symmetrical, predominantly male lipomatosis, predominantly cervico-facio-truncal [4].

If, for some, the term alcohol-dependent deserves to be added in the definition, as the frequency of chronic intoxication is found, the term benign should for others be abandoned because of the potential complications related to the disease and alcoholism. It mainly occurs in men between 35 and 50 years old. Familial cases are reported and are transmitted according to the autosomal dominant mode with variable penetrance. Alcoholic withdrawal is also, paradoxically, reported. The disease may thus appear during voluntary detoxification or after prolonged hospitalization for illness or trauma. The onset of the disease after trauma is also reported. The evolution of the disease is quite stereotyped [5].

After relatively rapid growth over several years, the progression of the disease slows down or stabilizes. The evolution by thrusts is also described. An acute form, developing in 15 days, is reported in the literature. Stopping alcohol does not cause the lesions to regression. Clinically Lipomatous masses are painless, except in cases of nerve or mediastinal compression. Although flexible to palpation, their texture is denser than that of isolated lipomas. The absence of a capsule and the infiltrating character are two major characteristics that distinguish the lipomatous masses from the disease from the simple lipomas. They partly explain the difficulties of surgical treatment [6].

Sometimes the lipomatous masses are limited by a pseudo-capsule that results from compression of the perimysium or surrounding connective tissue. The skin in relation to lipomas is, in most cases, normal. Sometimes it is erythematous or telangiectatic. Enzi's classification distinguishes two types depending on the location of the disease [7]. In type 1, the lipomatous masses are deep, with subcutaneous fat atrophy. There is a risk of compression for mediastinal locations (cave syndrome, tracheal compression). The location of lipomas in the cervical, sus-clavicular and deltoid region gives a pseudo-athletic appearance to the patient. In type 2, lipomatosis is diffuse and subcutaneous. There is no compression syndrome. It is of interest to the trunk, abdomen and root of the limbs. The appearance of the patient thus mimics obesity. There is an overweight. Carlsen proposes a third type: a congenital form essentially located at the trunk. No cervical damage is found in 0 to $30 \%$ of cases and is more common in women. An extension of the disease to the larynx is described.

Anatomopathological the tissue has the same characteristics as normal adipose tissue. Fibrous partitions are thicker [8]. The appearance is close to a lipoatrophy with many small fat cells.
Anatomopathological examination of exegesis parts is systematic. Liposuction is prohibited if in doubt about sarcomatous (very rare) malignant degeneration.

The disease is frequently associated with liver disease, glucose intolerance, hyper uricemia and cancer of the upper aerodigestive tract. Surgical treatment is the only effective treatment. Interventions are often long and tedious, which is why the splitting of interventions is essential. Surgery is difficult because of the volume of fatty masses, the dissemination of lipomas and their infiltration into nearby tissues due to the absence of a capsule. Computed tomography can predict these difficulties [9].

Sometimes Liposuction appears to be an attractive alternative to surgery on the surface because it is simple, less dilapidated, reproducible, and with minimal scarring ransom. The postoperative follow-up is simpler, with a lower frequency of hematomas, less blood loss, less seroma and shorter operating time.

\section{CONCLUSION}

L.B disease is considered difficult to treat, as it occurs in middle-aged subjects, often weakened by alcohol poisoning and by the infiltrating and hemorrhagic nature of lipomatous masses. All patients must benefit from specialized and personalized medical care before any surgery. The total cooperation of the patient is required and is an indispensable prerequisite for surgery. Alcoholic withdrawal, correction of metabolic disorders, establishment of hygienic rules are requested. Screening for VADS cancer should be discussed. Surgery is only considered after alcohol withdrawal. It is planned, split.

\section{REFERENCES}

1. Launois PEBR. De l'adénolipomatose symétrique. Bull Soc Med Hop Paris. 1898; 1:298-318.

2. Luscher NJ, Prein J, Spiessl B. Lipomatosis of the neck (Madelung's neck). Ann Plast Surg 1986; 16:502-8

3. 3-Enzi G. Multiple symmetric lipomatosis: an updated clinical report. Medicine (Baltimore) 1984; 63:56-64.

4. Brackenbury ET, Morgan WE. Surgical management of Launois-Bensaude syndrome. Thorax. 1997 Sep;52(9):834.

5. Carlin MC, Ratz JL. Multiple symmetric lipomatosis: treatment with liposuction. J Am Acad Dermatol. 1988;18(2 Pt 1):359-62.

6. Ruzicka T, Vieluf D, Landthaler M, Braun-Falco O. Benign symmetric lipomatosis LaunoisBensaude: report of ten cases and review of the literature. Journal of the American Academy of Dermatology. 1987 Oct 1;17(4):663-74.

7. Debaere PA, Vallon-Vandwalle C, Vandervoord J, Decoopman B, Vandenbussche F. 20 patients operated on for Launois-Bensaude disease. 
InAnnales de chirurgie plastique 1981 (Vol. 26, No. 2, p. 180).

8. Gate A, Robert JM. Launois-Bensaude syndrome. (About 12 clinical cases). Ann Chir Plast. 1966 Sep; 11:193-7.

9. Shetty C, Avinash K, Auluck A, Mupparapu M. Multiple symmetric lipomatosis (MSL) of neck in a child (Madelung's disease): report of a rare presentation. Dentomaxillofac Radiol. 2007; 36:514.

10. Parmar C, Blackburn C. Madelung's disease: an uncommon disorder of unknown aetiology? $\mathrm{Br} \mathrm{J}$ Oral Maxillofac Surg. 1996; 34:467-70.

11. Perrault M, Dry J, Baux S, Pradalier A. Symmetrical lipomatosis (Launois-Bensaude disease). Ann Med Interne (Paris) 1970; 121: 1916.

12. Monnier-Kuhn PGI, Morgon A, Bernard PA. La forme aigüe de l'adénolipomatose de Launois et Bensaude. J Fr Otorhinolaryngol. 1971; 20:1160-1.

13. Boozan JA, Maves MD, Schuller DE. Surgical management of massive benign symmetric lipomatosis. Laryngoscope. 1992; 102:94-9.

14. Donhauser G, Vieluf D, Ruzicka T, Braun-Falco O. Benign symmetric Launois-Bensaude type III lipomatosis and Bureau-Barriere syndrome. Hautarzt. 1991; 42:311-4.

15. Carlsen A, Thomsen M. Different clinical types of lipomatosis. Case report. Scand J Plast Reconstr Surg. 1978; 12:75-9.

16. Findlay GH, Duvenage M. Acquired symmetrical lipomatosis of the hands - a distal form of the Madelung-Launois-Bensaude syndrome. Clin Exp Dermatol. 1989;14:58—9.
17. Moretti JA, Miller D. Laryngeal involvement in benign symmetric lipomatosis. Arch Otolaryngol. 1973;97:495-6.

18. Requena L, Hasson A, Arias D, Martin L, Barat A. Acquired symmetric lipomatosis of the soles. A plantar form of the Madelung-Launois-Bensaude syndrome. J Am Acad Dermatol. 1992;26(5 Pt 2):860-2

19. Bell GW, High AS, Hutchinson D. Madelung's disease, an asymmetric presentation. $\mathrm{Br} \mathrm{J}$ Oral Maxillofac Surg. 1999;37:151-2.

20. Darsonval V, Duly T, Munin O, Houet JF. Surgical treatment of Launois-Bensaude disease. The value of liposuction. Ann Chir Plast Esthet. 1990; 35:128-33

21. Greene ML, Glueck CJ, Fujimoto WY, Seegmiller JE. Benign symmetric lipomatosis (LaunoisBensaude adenolipomatosis) with gout and hyperlipoproteinemia. Am J Med. 1970; 48:239-46.

22. Enzi G, Favaretto L, Martini S, Fellin R, and Baritussio A, Baggio G. Metabolic abnormalities in multiple symmetric lipomatosis: elevated lipoprotein lipase activity in adipose tissue with hyperalphalipoproteinemia. J Lipid Res 1983;24:566-74

23. Pollock M, Nicholson GI, Nukada H, Cameron S, Frankish P. Neuropathy in multiple symmetric lipomatosis. Madelung's disease. Brain. 1988; 111:1157-71.

24. La maladie de Launois-Bensaude: description, prise en charge. À propos de dix patients opérés About 10 cases of Launois-Bensaude disease $\mathrm{J}$. Pauchot a*, A. Golay b, R. Gumener c, D. Montandon C, B. Pittet C. Annales de chirurgie plastique esthétique. 2009; 54 : 135-145. 